\title{
ANALISIS KOMPONEN FISIK TERHADAP KEMAMPUAN SHOOTING
}

\author{
Jusran $\mathrm{S}^{1}$ \\ Email : $\underline{\text { Jusrankaka04@gmail.com }}$ \\ ${ }^{1}$ STKIP Paris Barantai
}

\begin{abstract}
Abstrack
Penelitian yang akan dilakukan adalah (1) Untuk mendeskripsikan komponen fisik terhadap kemampuan shooting pada club sepakbola Spartax Fc Kotabaru. (2) Untuk mendeskripsikan kekuatan terhadap kemampuan shooting pada club sepakbola Spartax Fc Kotabaru. (3) Untuk mendeskripsikan keseimbangan terhadap kemampuan shooting pada club sepakbola Spartax Fc Kotabaru. (4) Untuk mendeskripsikan koordinasi mata-kaki terhadap kemampuan shooting pada club sepakbola Spartax Fc Kotabaru. Metode penelitian deskriftif kualitatif, karena dalam pendekatan deskriftif kualitatif. Populasinya adalah seluruh pemain sepakbola Spartax Fc Kotabaru. Sampel yang digunakan adalah sebanyak 25 pemain Spartax Fc Kotabaru. Teknik penentuan sampel adalah dengan menggunakan teknik Sampel Jenuh. Variabel yang terlibat dalam penelitian ini yaitu variabel bebas komponen fisik dan variabel terikat kemampuan shooting. Instrument tes yang digunakan yaitu komponen fisik terdiri dari kekuatan, keseimbangan, dan koordinasi mata-kaki sedangkan kemampuan shooting dengan menggunakan tes menendang kearah sasaran yang telah di tentukan sebanyak 3 kali percobaan. Teknik analisis data yang digunakan adalah analisis deskriptif persentase, dan analisis koefisien korelasi pearson product moment (r) pada taraf signifikan $\alpha$ $=0,05$. Hasil penelitian menunjukkan bahwa 1) Komponen fisik pada pemain sepakbola Spartax Fc Kotabaru dengan skor rata-rata sebesar 0,560 dalam kategori sedang; 2) Kemampuan shooting pada club sepakbola Spartax Fc Kotabaru dengan nilai rata-rata sebesar 0,191 dalam kategori rendah; 3) Ada keterkaitan yang signifikan komponen fisik dengan kemampuan shooting pada club sepakbola Spartax Fc Kotabaru dengan nilai r sebesar 0,159 dalam kategori rendah; 4) Ada keterkaitan yang signifikan komponen fisik dengan kemampuan shooting pada club sepakbola Spartax Fc Kotabaru dengan nilai r sebesar 0,210 dalam kategori rendah $(\mathrm{P}<\alpha 0,05)$.
\end{abstract}

Kata Kunci : Analisis, Komponen Fisik, Kemampuan Shooting.

\section{Abstrack}

The research that will be carried out is (1) To describe the physical component of the shooting ability at the Kotabaru Spartax Fc football club. (2) To describe the strength of the shooting ability at Spartax FC Kotabaru football club. (3) To describe the balance of shooting skills at the Spartax FC Kotabaru football club. (4) To describe the eye-foot coordination of the shooting ability at the Kotabaru Spartax Fc football club. Qualitative descriptive research method, because in a qualitative descriptive approach. The population is all football players Spartax Fc Kotabaru. The samples used were 25 players of Spartax Fc Kotabaru. The sample determination technique is to use the Saturated Sample technique. The variables involved in this study were the independent variable physical components and the dependent variable shooting ability. The test instrument used is the physical component consisting of strength, balance, and eye-leg coordination, while the shooting ability uses the kick test towards a predetermined target 3 times. The data analysis technique used is the percentage descriptive analysis, and the Pearson product moment ( $r$ ) correlation coefficient analysis at the significant level $\alpha=0.05$. The results showed that 1) the physical components 
of the football player Spartax Fc Kotabaru with an average score of 0.560 in the medium category; 2) The shooting ability at the Kotabaru Fc Spartax football club with an average score of 0.191 in the low category; 3) There is a significant relationship between the physical component and the shooting ability at the Spartax Fc Kotabaru football club with an $r$ value of 0.159 in the low category; 4) There is a significant correlation between the physical component and the shooting ability at the Spartax Fc Kotabaru football club with an $r$ value of 0.210 in the low category $(P<\alpha 0.05)$.

Keywords: Analysis, Physical Components, Shooting Ability.

\section{A. Pendahuluan}

Sepakbola adalah salah satu cabang olahraga yang paling digemari disegala lapisan masyarakat Indonesia, dari anak-anak sampai dewasa terutama laki-laki. Banyak laki-laki yang menyalurkan hobinya dengan bermain sepakbola. Anak laki-laki secara psikologis akan lebih tertarik pada permainan yang memerlukan berbagai jenis gerakan karena sebagian besar anak laki-laki selalu mempertontonkan keterampilan geraknya dalam berbagai situasi. Sepakbola yang dimainkan oleh dua tim, yang masing-masing beranggotakan sebelas orang. Pemain sepakbola dituntut menguasai teknik, taktik, dan strategi yang benar serta konsisten atas dasar koordinasi kaki untuk tetap menguasai bola untuk mendukung tercapainya tujuan dalam permainan sepakbola. Kemampuan menendang bola akan ikut menentukan suatu tim dalam memperoleh kemenangan dalam suatu pertandingan. Prinsip dasar permainan sepak bola adalah "membuat gol ke gawang lawan dan mencegah gol ke gawang sendiri. Masingmasing regu atau kesebelasan berusaha memasukan bola sebanyak-banyaknya kedalam gawang lawan dan mempertahankan gawangnya sendiri agar tidak kemasukan" (Sarumpaet, 1992:2). Shooting dalam sepakbola merupakan salah satu teknik yang memegang peranan penting dalam permainan sepakbola. Karena tujuan shooting adalah untuk memasukan bola ke gawang lawan dengan tujuan memperoleh poin untuk merubah keadaan atau sering di sebut skor. Menurut Sucipto (2000:20) memberikan penjelasan mengenai shooting, yaitu "tendangan yang di awali meletakkan kaki tumpu di samping dan sejajar dengan bola. Lalu posisi lutut agak sedikit ditekuk, denga kaki yang digunakan untuk menendang di ayunkan ke arah belakang. Dan pada bagian kaki yang mengenai bola, ialah punggung kaki”. Selesai melakukan tendangan, jaga keseimbangan tubuh menggunakan kedua tangan. Jadi, shooting adalah salah satu cara untuk memasukkan bola atau menciptakan gol ke gawang lawan dengan menggunakan kaki yang terkuat. Upaya untuk meningkatan prestasi sepakbola perlu dimulai dengan melalui pembinaan secara berkelanjutan yang dimulai sejak usia dini. Perkembangan pembinaan persepakbolaan di Indonesia secara kuantitas, pada saat ini cukup menggembirakan. Hal ini terbukti dengan munculnya club-club Sepakbola di daerah kotabaru dalam ajang turnamen sepakbola bupati cup tahun 2018. Club Spartax FC Kotabaru tidak bisa melaju ke babak 8 besar karena di kalahkan oleh club PS Salino. Salah satunya adalah Club Spartax FC Kotabaru yang mempunyai visi untuk mengembangkan olahraga sepakbola melalui kegiatan Pembinaan hal ini bertujuan untuk mengembangkan bakat para pemain yang berkeahlian di bidang sepakbola khususnya dan tanpa mengganggu kegiatan sehari - hari.

Spartax FC Kotabaru sendiri sudah sering mengikuti kompetisi Antara club-club sepakbola yang ada di Kotabaru, Namun hasilnya belum begitu memuaskan. Masalahmasalah yang dapat mempengaruhi diantaranya yaitu, kualitas pelatih, sarana dan prasarana yang dimiliki, dukungan pemerintah dan masyarakat, serta kualitas pemain itu sendiri. Masalah terpenting dalam upaya peningkatan prestasi dalam sepakbola adalah peningkatan kualitas pemain. Dalam upaya peningkatan kualitas pemain, diperlukan peningkatan kualitas pembinaan dan pelatihan. Penguasaan teknik dasar permainan sepakbola perlu diutamakan dalam rangka pencapaian prestasi yang optimal. Salah satu permasalahan yang penting dalam bermain sepakbola adalah tingkat penguasaan keterampilan teknik dasar bermain sepakbola, 
dalam hal ini adalah menendang bola (Shooting). Mengingat pentingnya keterampilan menendang bola (shooting) tersebut, maka keterampilan menendang bola ini harus mendapat perhatian yang serius dalam pembinaan prestasi sepakbola. Setiap pemain sepakbola perlu dilatih keterampilan menendang bola (Shooting). Demikian juga pada para pemain Spartax FC Kotabaru, dalam rangka untuk meningkatkan prestasinya, shooting atau menendang bola pada para pemainnya harus ditingkatkan. Pelatih harus memberikan latihan shooting secara intensif dengan program yang benar. Latihan yang diberikan harus memperhatikan faktor kondisi fisik yang mempengaruhi kemampuan shooting. Kemampuan shooting, sangat dipengaruhi oleh unsur kondisi fisik pemain. Unsur kondisi fisik yang mempengaruhi kemampuan shooting, diantaranya kekuatan dan ketepatan. Tujuan dari menendang bola dapat terwujud dengan menerapkan porsi latihan yang baik. Selain itu dengan cara melakukan gerakan squat jump, keseimbangan dan koordinasi mata dan kaki, agar pada saat melakukan shooting bola terarah dengan sasaran yang dituju. Berdasarkan hasil observasi yang saya lihat pada bulan agustus 2018, masih diperoleh bahwa pada saat melakukan shooting tidak terlatih sehingga menyebapkan tendangan para pemain tidak maksimal. Pada saat pertandingan berlangsung terdapat pemain kurangnya menguasai teknik tendangan shooting yang baik, perkenaaan bola saat melakukan shooting. Selain itu metode yang digunakan pelatih kurang bervariatif, guna meningkatkan power otot tungkai pemain. Apabila ini tidak diatasi, maka akan merugikan bagi club pada saat pertandingan.

\section{B. Metode}

Penelitian ini adalah penelitian deskriptif kuantitatif, di mana peneliti hanya ingin mengungkapkan data yang diperoleh melalui tes dan pengukuran dilapangan tanpa memberikan perlakuan (treatment) terhadap variabel bebas yang diamati. Setelah data terkumpul baru dilakukan dianalisis secara statisti untuk melihat keeratan hubungan variabel bebas dengan variabel terikat. Variabel dapat didefinisikan sebagai atribut dari seseorang atau objek yang mempunyai variasi antar satu orang dengan yang lain atau objek dengan objek lain. Adapun variabel penelitian yang digunakan dalam penelitian ini antara lain sebagai berikut:1) Variabel Bebas (X): a. Komponen fisik: Kekuatan, Keseimbangan, Koordinasi Mata-kaki 2) Variabel Terikat (Y): a. Kemampuan Shooting. Populasi Menurut Mia Kusumawati (2015: 93) Populasi adalah totalitas objek penelitian yang dapat berupa manusia, hewan, tumbuhan, dan benda mempunyai kesamaan untuk dijadikan data penelitian. Populasi adalah wilayah generelisasi yang terdiri atas:obyek/subyek yeang mempunyai kualitas dan karakteristik tertentu yang di tetapkan oleh peneliti untuk dipelajari dan kemudian di tarik kesimpulannya. Sugiyono (2014:80), adapun populasi dalam penelitian ini adalah seluruh Anggota Club Spartax FC Kotabaru sebanyak 25 orang Sampel Pengertian sampel menurut Sukardi (2012:54) adalah sebagian dari jumlah populasi yang di pilih untuk sumber data. Menurut Gunawan (2013:2) yang di maksud sampel adalah sebagian atau wakil populasi di teliti atau cara sederhana sampel panelitian adalah sebagian dari populasi yang di ambil sebagai sumber data dan dapat mewakili seluruh populasi.Berpijak pada pernyataan tersebut maka pengambilan sampel dalam penelitian ini adalah total sampling jenuh yang mana teknik penentuan sampel bila semua anggota populasi digunakan sebagai sampel. Hal ini sering dilakukan bila jumlah populasi relatif kecil kurang dari 30 orang. Adapun instrumen penelitian Pengukuran Kekuatan dengan test Squat Jump 30 detik. Pengambilan data keseimbangan (Stork Stand), Untuk mengukur koordinasi mata dan kaki memantulkan bola kesasaran selama 10 detik, Tes menembak bola (Shooting) kesasaran berjarak 16,5 meter. 


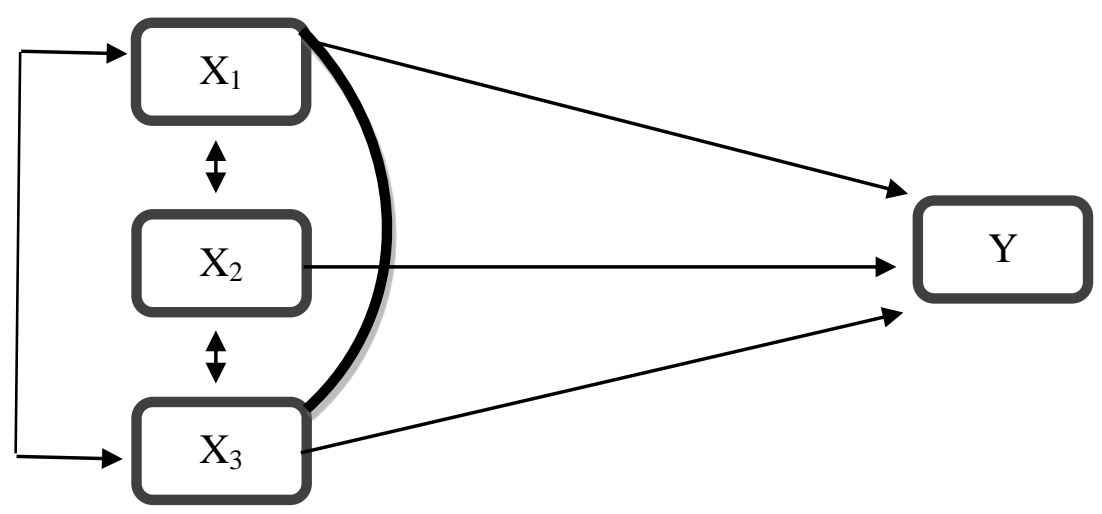

Gambar 1: Paradigma ganda tiga variable independen Sumber: Sugiyono (2013:44)

Keterangan :

$\mathrm{X}_{1} \quad$ : Kekuatan

$\mathrm{X}_{2}$ : Keseimbangan

$\mathrm{X}_{3} \quad$ : Koordinasi mata dan kaki

Y : Shooting

Analisis regresi berganda digunakan oleh peneliti, dimana penelitian ini bermaksud menganalisis bagaimana keadaan variabel dependen dengan dua variabel independen. Model analisis yang akan digunakan untuk memperolen penjelasan tentang kekuatan variabel penentu/independen terhadap perubahan variabel terikat/dependen adalah metode regresi berganda dengan program SPSS (Statistical Pacekage For The Social Sciencess) versi 23 for windows pada taraf signifikansi $\mathrm{a}=0,05=95 \%$ (Singgih Santoso 2016).

\section{Hasil dan Pembahasan}

Table.1. Hasil analisis deskriptif data komponen fisik terhadap kemampuan shooting pada club sepakbola Spartax FC Kotabaru.

\begin{tabular}{lrrrr} 
Statistik & Kekuatan & \multicolumn{1}{c}{$\begin{array}{c}\text { Keseimb } \\
\text { angan }\end{array}$} & $\begin{array}{c}\text { Koordinasi } \\
\text { mata-kaki }\end{array}$ \\
\hline$N$ & 25 & 25 & 25 & Shooting \\
Mean & 22,56 & 8,87 & 5,24 & 6,72 \\
Median & 23 & 8 & 5 & 6 \\
$S D$ & 3,95 & 4,98 & 1,64 & 3,42 \\
Minimum & 12 & 2 & 2 & 2 \\
Maximum & 28 & 21 & 8 & 14 \\
\hline
\end{tabular}

Berdasarkan hasil analisis deskriptif data pada di atas, maka dapat di uraikan sebagai berikut :

a. Untuk data kekuatan diperoleh nilai rata-rata (mean) sebesar 22,56 (median) 23, hasil simpangan baku (standar deviasi) sebesar 3,95, nilai terendah (minimal) sebesar 12, dan nilai terttinggi (maksimal) sebesar 28.

b. Untuk data keseimbangan diperoleh nilai rata-rata (mean) sebesar 8,87, (median)sebesar 8, hasil simpangan baku (standar deviasi) sebesar 4,98, nilai terendah (minimal) sebesar 2, dan nilai terttinggi (maksimal) sebesar 21 . 
c. Untuk data koordinasi mata-kaki diperoleh nilai rata-rata (mean) sebesar 5,24, (median) 5, hasil simpangan baku (standar deviasi) sebesar 1,64, nilai terendah (minimal) sebesar 2, dan nilai tertinggi (maksimal) sebesar 8 .

d. Untuk data kemampuan shooting diperoleh nilai rata-rata (mean) sebesar 6,72, (median) 6 hasil simpangan baku (standar deviasi) sebesar 3,42, nilai terendah (minimal) sebesar 2, dan nilai terttinggi (maksimal) sebesar 14.

Table. 2. Hasil uji normalitas data komponen fisik terhadap kemampuan shooting pada club sepakbola Spartax FC Kotabaru.

\begin{tabular}{llccc} 
& \multicolumn{1}{c}{ Variabel } & Statistik & Sig & Ket \\
\hline 1 & Kekuatan & 0.122 & 0.200 & Normal \\
2 & Keseimbangan & 0.167 & 0.070 & Normal \\
3 & Koordinasi mata-kaki & 0.162 & 0.090 & Normal \\
4 & Shooting & 0.143 & 0.198 & Normal \\
\hline
\end{tabular}

Berdasarakan data tabel tersebut yang merupakan hasil pengujian normalitas data pada tiaptiap variabel penelitian, dapat diuraikan sebagai berikut :

a. Dalam pengujian normalitas data kekuatan diperoleh nilai Shapiro-wilk $Z=0.122$ dengan probabilitas $(P)=0.200$ lebih besar dari pada nilai $a=0,05$. Dengan demikian data kekuatan yang diperoleh berdistribusi normal.

b. Dalam pengujian normalitas data keseimbangan diperoleh nilai Shapiro-wilk $Z=0.167$ dengan probabilitas $(P)=0.070$ lebih besar dari pada nilai $a=0,05$. Dengan demikian data keseimbangan yang diperoleh berdistribusi normal.

c. Dalam pengujian normalitas data koordinasi mata-kaki diperoleh nilai Shapiro-wilk $\mathrm{Z}=$ 0.162 dengan probabilitas $(P)=0.090$ lebih besar dari pada nilai $a=0,05$. Dengan demikian data koordinasi mata-kaki yang diperoleh berdistribusi normal.

d. Dalam pengujian normalitas data kemampuan shooting diperoleh nilai Shapiro-wilk $\mathrm{Z}=$ 0.143 dengan probabilitas $(\mathrm{P})=0.198$ lebih besar dari pada nilai $\mathrm{a}=0,05$. Dengan demikian data kekuatan, keseimbangan, koordinasi mata-kaki, kemampuan shooting yang diperoleh berdistribusi normal.

Tabel 3. Hasil analisis regresi ganda komponen fisik terhadap kemampuan shooting pada club sepakbola Spartax FC Kotabaru.

\begin{tabular}{|c|c|c|c|c|c|c|}
\hline Variabel & $\mathrm{R}$ & $\mathrm{R}^{2}$ & $\mathrm{P}_{\text {value }}$ & $\mathrm{F}$ & Tingkat & Kategori \\
\hline $\begin{array}{l}\text { Kekuatan }\left(\mathrm{X}_{1}\right), \\
\text { Keseimbangan }\left(\mathrm{X}_{2}\right) \text {, } \\
\text { Koordinasi mata- } \\
\text { kaki }\left(\mathrm{X}_{3}\right) \\
\text { Kemampuan } \\
\text { shooting }(\mathrm{Y}) \\
\end{array}$ & 0.748 & 0.560 & 0.001 & 8.911 & $56,0 \%$ & Sedang \\
\hline
\end{tabular}

Berdasarkan tabel IV.3. Di atas terlihat bahwa hasil analisis komponen fisik meggunakan analisis regresi ganda, diperoleh nilai $\mathrm{R}=0.748, \mathrm{R}^{2}=0.560, \mathrm{P}_{\text {value }}=0.001, \mathrm{~F}=$ 8.911, Tingkat 56,0\%. Berarti analisis komponen fisik terhadap kemampuan shooting pada club sepakbola Spartax FC Kotabaru. Termasuk katagori yang sedang. 
Pembahasan

Analisis yang signifikan kekuatan, keseimbangan, koordinasi mata-kaki dengan kemampuan shooting pada club sepakbola Spartax FC Kotabaru. Hasil analisis statistik menunjukkan bahwa ada analisis yang signifikan antara kekuatan, keseimbangan, koordinasi mata-kaki dengan kemampuan shooting. Apabila hasil penelitian ini dikaitkan dengan teori dan kerangka berpikir yang mendasarinya, maka pada dasarnya hasil penelitian ini mendukung dan memperkuat teori dan hasil-hasil penelitian terdahulu yang sudah ada. Seorang pemain Spartax FC Kotabaru yang memiliki kekuatan, keseimbangan, koordimasi mata-kaki yang baik akan mampu melakukan shooting dengan baik pula. Dalam hal ini, kekuatan, keseimbangan, koordinasi mata-kaki akan memberikan sumbangan yang berarti dalam shooting. Oleh karena itu, dapat disimpulkan bahwa untuk menghasilkan kemampuan shooting yang baik, maka kekuatan, keseimbangan, koordinasi mata-kaki sangat memegang peranan penting dalam terlaksannya kemampuan shooting pada permainan sepakbola. Dari penjelasan diatas dapat disimpulkan bahwa seorang pemain Spartax FC Kotabaru yang memiliki kekuatan, keseimbangan, koordinasi mata-kaki yang baik akan mampu melakukan shooting dengan baik. Jadi apabila pemain memiliki kekuatan, keseimbangan, dan koordinasi mata-kaki yang baik maka akan mampu melakukan kemampuan shooting dengan lebih baik pula.

\section{Simpulan}

Sebagai tindak lanjut akhir dari suatu karya ilmiah adalah penarikan simpulan. Arah dari kesimpulan yang jelas dapat memberikan kemudahan bagi pembaca di dalam penelitian ini secara sederhana dapat di rinci sebagai berikut: Komponen fisik terhadap kemampuan shooting pada club sepakbola Spartax FC Kotabaru sebesar 56,0\%. Kekuatan terhadap kemampuan shooting pada club Spartax FC Kotabaru sebesar 19,1\%. Keseimbangan terhadap kemampuan shooting pada club Spartax FC Kotabaru sebesar 15,9\%. Koordinasi mata-kaki terhadap kemampuan shooting pada club sepakbola Spartax FC Kotabaru sebesar 21,0\%

\section{Daftar Pustaka}

Afrian, H., \& Hariadi, N. (2018). Implementasi Sport Search Untuk Mengidentifikasi Bakat Calon Olahragawan Berprestasi. Jurnal Porkes, 1(1), 27-31.

Hidayatullah, F. (2017). Ketepatan Penggunaan Istilah Pada Pembelajaran Pendidikan Jasmani Materi Permainan Bola Besar Siswa Sekolah Menengah Pertama Negeri Kecamatan Bangkalan. JOURNAL PROCEEDING, 1(1).

Iqbal, R., Julianti, R. R., \& Dimyati, A. (2019). Pengguna Model Pembelajaran Teman Sebaya (Peer Teaching) Dalam Teknik Dribble Pemainan Bola Basket. Jurnal Porkes, 2(2), 37-43.

Jumaking, J. (2020). Pengaruh Daya Ledak Tungkai, Koordinasi Mata Kaki Dan Percaya Diri Terhadap Kemampuan Shooting Ke Gawang Dalam Permainan Sepakbola Pada Siswa Sman 2 Kolaka. Kinestetik: Jurnal Ilmiah Pendidikan Jasmani, 4(1), 122-131.

Kusumawati, M. (2015). Penelitian Pendidikan PENJASORKES. Bandung: Alfabeta

Muis, A. (2014). Analisis Kondisi Fisik Terhadap Keterampilan Menendang Bola Ke Arah Gawang (Shooting). Jurnal Kesehatan Olahraga, 2(3).

Pammusureng, P. (2015). Analisis Komponen Kondisi Fisik Terhadap Keterampilan Shooting Dalam Permainan Bolabasket Siswa Ma As' Adiyah Putra Pusat Sengkang Kab. Wajo (Doctoral Dissertation, Pascasarjana).

Prayoga, H. D., Fitrianto, A. T., \& Habibie, M. (2020). Perbandingan Kemampuan Fisik Dasar Petinju Nasional Dengan Petinju Daerah. Jurnal Porkes, 3(2), 149-158.

Sucipto. (2000). Sepakbola. Departemen Pendidikan dan Kebudayaan:

Direktorat Jendral Pendidikan dan Kebudayaan

Sugiyono. (2013). Statistik untuk penelitian. Bandung: Alfabeta 
Sukardi. 2015. Evaluasi pendidikan. Jakarta: Bumi Aksara.

Wijayanto, E. Z. (2012). Pengaruh Pembelajaran Permainan Bola Besar Terhadap Tingkat Kesegaran Jasmani. ACTIVE: Journal of Physical Education, Sport, Health and Recreation, 1(1).

Widiastuti, S. S. (2019). Mengenal Permainan Olahraga Bola Besar. Myria Publisher. 